\title{
Preparation and characterization of nanostructured copper bismuth diselenide thin films from a chemical route
}

\author{
R H BARI and L A PATIL* \\ P.G. Department of Physics, Pratap College, Amalner 425 401, India
}

MS received 1 July 2009; revised 9 September 2009

\begin{abstract}
Thin films of copper bismuth diselenide were prepared by chemical bath deposition technique onto glass substrate below $60^{\circ} \mathrm{C}$. The deposition parameters such as time, temperature of deposition and $\mathrm{pH}$ of the solution, were optimized. The set of films having different elemental compositions was prepared by varying $\mathrm{Cu} / \mathrm{Bi}$ ratio from 0·13-1·74. Studies on structure, composition, morphology, optical absorption and electrical conductivity of the films were carried out and discussed. Characterization includes X-ray diffraction (XRD), scanning electron microscopy (SEM), atomic force microscopy (AFM), energy dispersive X-ray analysis (EDAX), absorption spectroscopy, and electrical conductivity. The results are discussed and interpreted.
\end{abstract}

Keywords. Copper bismuth diselenide; thin films; chemical bath deposition; deposition parameters.

\section{Introduction}

Ternary chalcopyrite semiconductors are interesting because of their technological applications in electro-optical and photovoltaic devices. The copper bismuth chalcopyrite systems show rectification characteristics at the metal point contact and usually crystallize in chalcopyrite structure with peculiar non-linear properties (Shay and Wernick 1975; Abdelghany et al 1990). Their physicochemical properties have not been studied in detail, however, the electrical and optical properties of some of these compounds in crystalline state have now appeared in the literature (Abou El-Ela and Abdelmohsen 1982; Pawar et al 1986; Abdelghany et al 1990; Sutrave et al 1996; Sonawane et al 2004).

This article presents preparation of one of the chalcopyrite systems, $\mathrm{CuBiSe}{ }_{2}$, in thin form by employing a simple chemical bath deposition technique.

The chemical bath deposition technique is the simplest and is capable of handling large area fabrication at low cost. In this technique, wastage of material is minimum and there is no need to handle the poisonous gases like $\mathrm{H}_{2} \mathrm{Se}$ and $\mathrm{H}_{2} \mathrm{~S}$.

Efforts have been made here to synthesize $\mathrm{CuBiSe}_{2}$ thin films by varying chemical compositions. The parameters are optimized for uniform deposition of the films. The effect of composition on structural, optical and electrical properties of this material was studied. Various characterization techniques such as XRD, optical spectroscopy, scanning electron microscopy and atomic force microscopy were employed to study the films.

\footnotetext{
*Author for correspondence (plalchand_phy_aml@yahoo.co.in)
}

\section{Experimental}

The chemical bath deposition technique was used to deposit thin films of copper bismuth diselenide on glass substrate. The starting materials used were cupric chloride, bismuth nitrate, elemental selenium, and sodium sulphite. Triethanolamine (TEA) was used as a complexing agent. Sodium hydroxide and ammonia solutions were used to adjust $\mathrm{pH}$ of the reaction mixture. To obtain good quality films, time, temperature of deposition and $\mathrm{pH}$ of the solution were optimized. The optimum time, temperature and $\mathrm{pH}$ were observed to be $1 \mathrm{~h}, 60^{\circ} \mathrm{C}$ and 10 , respectively.

The process involved the reaction of $\mathrm{Cu}^{+}$and $\mathrm{Bi}^{3+}$ ions with $\mathrm{Se}^{2-}$ ions in deionized water solution. Elemental selenium $(99.95 \%)$ was dissolved in aqueous solution of sodium sulphite $(\mathrm{pH}>9)$ at $90^{\circ} \mathrm{C}$ to form a $\mathrm{Na}_{2} \mathrm{SeSO}_{3}$ solution. Bismuth nitrate solution was mixed with a separately prepared tetra amine copper. Sodium selenosulphate solution was then added to the solution bath. Samples were prepared by varying the volume of $\mathrm{Cu}$ precursor $(0 \cdot 1 \mathrm{M})$ keeping volumes of bismuth nitrate $(0 \cdot 1 \mathrm{M})$ and sodium selenosulphate $(0 \cdot 1 \mathrm{M})$ constant. In the solution, partially unstable $\mathrm{Na}_{2} \mathrm{SeSO}_{3}$ yielded $\mathrm{Se}^{2-}$ and $\mathrm{SO}_{3}{ }^{2-}$ ions. Sulphite ions reduced tetra amine copper and generated $\mathrm{Cu}^{+}$ions.

The structural properties of thin films were investigated by $\mathrm{X}$-ray diffraction (XRD) using $\mathrm{CuK} \alpha(\lambda=1 \cdot 5418 \AA)$ radiation. The optical absorption studies of the films were carried out using Shimadzu UV-2450 spectrophotometer. The scanning electron microscopic studies were carried out using JEOL model, JSM-6360A SEM. Elemental analysis was carried out with an EDAX using energy dispersive X-ray spectrophotometer (EDS). An AFM Nanoscope digital instrument with a silicon nitride cantilever was used to probe different portions of 
the film surface in 'contact mode AFM'. Electrical conductivity of the films was measured by using a d.c. two-probe method in the temperature range $313-423 \mathrm{~K}$.

\section{Results and discussion}

\subsection{Structural analysis}

Figure 1 shows diffractogram of sample 2 film scanned in the range of $20-80^{\circ}$. The XRD pattern reveals that $\mathrm{CuBiSe}_{2}$ film is polycrystalline in nature. The planes (106), (023)/ (103) corresponds to $\mathrm{CuBiSe}_{2}$ (JCPDS file no. 80-1592). There are some minor peaks corresponding to other phases such as $\mathrm{Bi}_{2} \mathrm{Se}_{3}$ and $\mathrm{Cu}_{2} \mathrm{Se}$ as indicated in the figure.

\subsection{Elemental analysis by EDS}

The quantitative elemental analyses of $\mathrm{CuBiSe}_{2}$ films were determined using energy dispersive analysis (EDAX) technique at room temperature. Table 1 shows the elemental composition of the films determined by EDS.

Theoretically expected stoichiometric composition of $\mathrm{CuBiSe}_{2}$ in terms of at $\%$ is $\mathrm{Cu}=25 \%, \mathrm{Bi}=25 \%$ and $\mathrm{Se}=50 \%$. It is clear from table 1 that the films are nonstoichiometric in nature. Ratio of at $\%(\mathrm{Cu}+\mathrm{Bi}) / \mathrm{Se}$ is the smallest in case of sample 2 as compared to other samples. The at $\%$ of $\mathrm{Cu}$ is expected to be equal to at $\%$ of $\mathrm{Bi}$ and the sum should be equal to 50 for the film to be stoichiometric. But this is not the case.

It is possible to vary the composition of the films as per the requirement and in turn optical properties could be systematically changed.

Figure 2 shows EDAX spectra of sample 2.

\subsection{Microstructural studies}

Figure 3 consists of SEM images representing surface morphology of the as synthesized copper bismuth diselenide films with different $\mathrm{Cu} / \mathrm{Bi}$ ratios. The images show rod like structures with narrow ends. The diameters of rods go on decreasing and lengths go on increasing with the increase of $\mathrm{Cu}$ at \%. Higher copper percentage may favour the growth along one direction and hence the increase in length along a particular direction. The average diameter of these rods was observed to be below $100 \mathrm{~nm}$. These rods may be the nanowires.

Table 2 represents the effect of composition on the rod length and diameter. Diameter corresponding to all the samples is $<100 \mathrm{~nm}$.

\subsection{Surface morphology}

Figure 4 represents the AFM pictures of the film having $(\mathrm{Cu}+\mathrm{Bi} / \mathrm{Se}$ ) ratio 1.22 (sample 2). There was agglomeration of particles in most of the cases as evident from the 2D micrographs. The root mean square value indicating the surface roughness of the film $\left(R_{\mathrm{gAFM}}\right)$ is calculated from different areas of the film. It was observed that the surface roughness of the film is $7.53 \mathrm{~nm} / 1 \mu \mathrm{m} \times 1 \mu \mathrm{m}$.

\subsection{Optical studies}

Optical absorption studies of $\mathrm{CuBiSe}_{2}$ films were carried out in the wavelength $(\lambda)$ range of $300-1100 \mathrm{~nm}$ at room temperature. The variation of absorbance with the wavelength $(\lambda)$ is shown in figure 5. The bandgap energies of the samples were calculated from the absorption edges of the spectra.

Table 3 summarizes the effect of at $\%$ of $\mathrm{Cu}$ (in $\mathrm{CuBiSe}_{2}$ ) on bandgap energy.

It is clear from figure 6 that bandgap energy increases with the increase of $\mathrm{Cu}$ concentration in $\mathrm{CuBiSe}_{2}$. Increase in bandgap energy could be attributed to decrease of diameters of nanorods with the increase of at $\%$ of copper.

From table 3, it is seen that bandgap energy increases with increase in film thickness.

\subsection{Electrical studies}

3.6a Electrical conductivity and activation energy: Electrical conductivity of the $\mathrm{CuBiSe}_{2}$ thin films was measured by using d.c. two-probe method in the temperature range

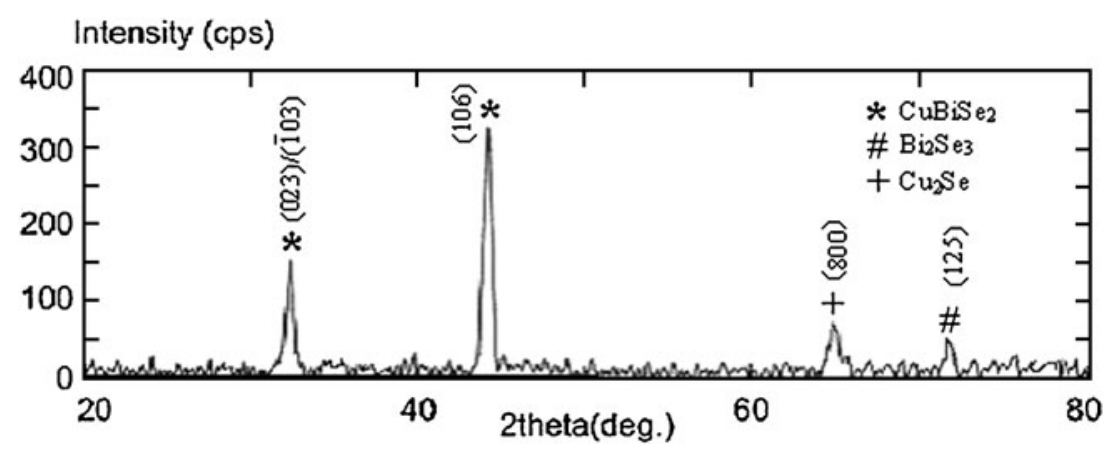

Figure 1. XRD of the sample. 
Table 1. Elemental composition of $\mathrm{CuBiSe}_{2}$ films.

\begin{tabular}{|c|c|c|c|c|c|}
\hline Sample No. & $\mathrm{Cu}($ at $\%)$ & $\mathrm{Bi}($ at $\%)$ & Se (at \%) & $\mathrm{Cu} / \mathrm{Bi}($ at $\%$ ) & $(\mathrm{Cu}+\mathrm{Bi} / \mathrm{Se})($ at $\%)$ \\
\hline 1. & $7 \cdot 27$ & $54 \cdot 52$ & $38 \cdot 01$ & $0 \cdot 13$ & $1 \cdot 63$ \\
\hline 2. & $17 \cdot 57$ & $37 \cdot 29$ & $45 \cdot 14$ & $0 \cdot 47$ & $1 \cdot 22$ \\
\hline 3. & $22 \cdot 03$ & $36 \cdot 19$ & $41 \cdot 78$ & $0 \cdot 61$ & $1 \cdot 39$ \\
\hline 4. & $33 \cdot 81$ & $35 \cdot 84$ & $30 \cdot 36$ & $0 \cdot 94$ & $2 \cdot 3$ \\
\hline 5. & $46 \cdot 52$ & $26 \cdot 68$ & $26 \cdot 80$ & $1 \cdot 74$ & $2 \cdot 7$ \\
\hline
\end{tabular}

313-423 K. Figure 6 shows variation of logarithm of conductivity with an inverse of temperature for various compositions of $\mathrm{CuBiSe}_{2}$. It is clear from figure 7 that the conductivity increases with increase in temperature indicating the semiconducting nature of $\mathrm{CuBiSe}_{2}$. Moreover, conductivity increases with increase in $\mathrm{Cu} / \mathrm{Bi}$ ratio in the composition. Figure 8 shows variation of electrical conductivity with $\mathrm{Cu} / \mathrm{Bi}$ ratio at a temperature of $448 \mathrm{~K}$. From table 4 it is seen that conductivity increases with increase in film thickness.

The activation energies were calculated from the slope of the graphs of logarithm of conductivity plotted against inverse of temperature and is tabulated in table 4. It is clear that the activation energy goes on decreasing with the increase of copper concentration in $\mathrm{CuBiSe}_{2}$ as shown in figure 9. Decrease of activation energy could be attributed to increase of conductivity with the increase of $\mathrm{Cu}$ concentration in $\mathrm{CuBiSe}_{2}$ compound.

3.6b Hall measurement: Hall measurements were made on five samples at room temperature. The values of carrier concentration and mobility are given in table 5 .

It is clear that the value of carrier concentration goes on increasing and mobility values go on decreasing with the increase of $\mathrm{Cu} / \mathrm{Bi}$ ratio. These measurements were made at a fixed temperature of $300 \mathrm{~K}$.

3.6c Thermoelectric power: Thermoelectric power (TEP) $S$ versus temperature curves are shown in figure 10 for five

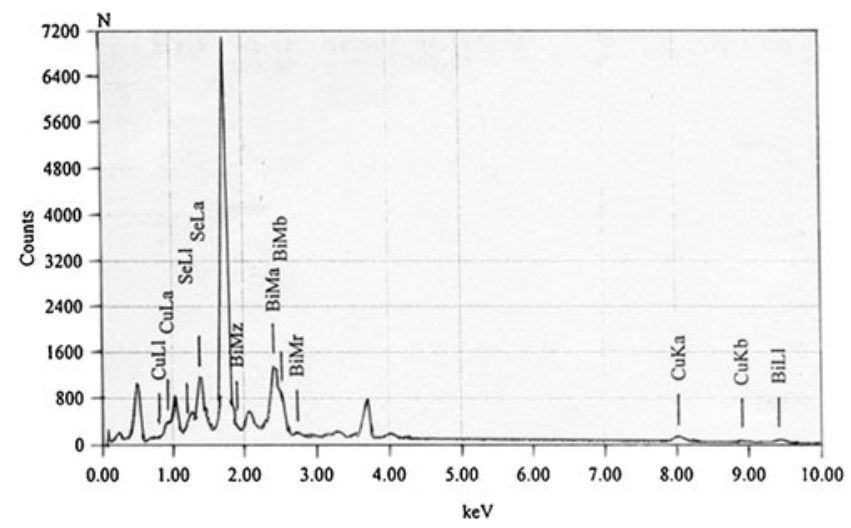

Figure 2. EDAX spectra of sample 2. different compositions of $\mathrm{CuBiSe}_{2}$. It is clear from the figure that TEP goes on increasing with increase in temperature for all the samples. TEP is negative for all samples during the temperature range of 275-385 K, indicating $n$ type semiconductivity. TEP values are presented in table 6 for different ratios of $\mathrm{Cu} / \mathrm{Bi}$ at a temperature of $385 \mathrm{~K}$.

Figure 11 shows variation of TEP with $\mathrm{Cu} / \mathrm{Bi}$ ratio at a temperature of $385 \mathrm{~K}$. It is clear from figure 11 that TEP becomes more negative with increase in $\mathrm{Cu} / \mathrm{Bi}$ ratio.

Formation of $\mathrm{CuBiSe}_{2}$ could be explained with the following chemical reactions:

(a) Formation of $\mathrm{Cu}^{+1}$ : There exists the possibility of reduction of $\mathrm{Cu}$ (II) to $\mathrm{Cu}$ (I) (Vogel 1978; Garica et al 1999) due to the presence of excess sodium sulphite,

$$
\begin{aligned}
& \mathrm{SO}_{3}^{2-}+2 \mathrm{OH}^{-} \rightarrow \mathrm{SO}_{4}^{2-}+\mathrm{H}_{2} \mathrm{O}+2 e^{-}, \\
& \mathrm{Cu}^{2+}+e^{-} \rightarrow \mathrm{Cu}^{+1} .
\end{aligned}
$$

(b) Formation of metal (copper) complex: Copper salt reacts with the reagent (triethanolamine) to form the metal complex (Chavan and Sharma 2005).

$$
\mathrm{Cu}^{1+}+n(\mathrm{TEA}) \rightarrow[\mathrm{Cu}(\mathrm{TEA}) n]^{1+} .
$$

(c) Formation of $\mathrm{Bi}^{3+}$ : By addition of TEA in bismuth nitrate solution, bismuth forms complex with TEA as:

$$
\begin{aligned}
& \mathrm{Bi}\left(\mathrm{NO}_{3}\right)_{3}+n(\mathrm{TEA}) \rightarrow \mathrm{Bi}[(\mathrm{TEA}) n]^{3+}, \\
& \mathrm{Bi}[(\mathrm{TEA}) n]^{3+} \rightarrow \mathrm{Bi}^{3+}+n(\mathrm{TEA}) .
\end{aligned}
$$

(d) Release of $\mathrm{Se}^{-}$: In the alkaline medium, the selenide ions are released as follows (Lokhande et al 1991; Sutrave et al 2000).

$$
\begin{aligned}
& \mathrm{Na}_{2} \mathrm{SeSO}_{3}+\mathrm{OH}^{-} \rightarrow \mathrm{Na}_{2} \mathrm{SO}_{4}+\mathrm{HSe}^{-}, \\
& \mathrm{HSe}^{-}+\mathrm{OH}^{-} \rightarrow \mathrm{H}_{2} \mathrm{O}+\mathrm{Se}^{2-} .
\end{aligned}
$$

(e) Formation of $\mathrm{CuBiSe}_{2}$ compound: Reaction of ingredients resulting from (2)-(4) would give the end product, $\mathrm{CuBiSe}_{2}$.

$$
\begin{gathered}
{[\mathrm{Cu}(\mathrm{TEA}) n]^{1+}+\mathrm{Bi}[(\text { TEA }) n]^{3+}+2 \mathrm{Se}^{2-}} \\
\rightarrow \mathrm{CuBiSe}_{2}+2 \text { nTEA }+ \text { by-product. }
\end{gathered}
$$



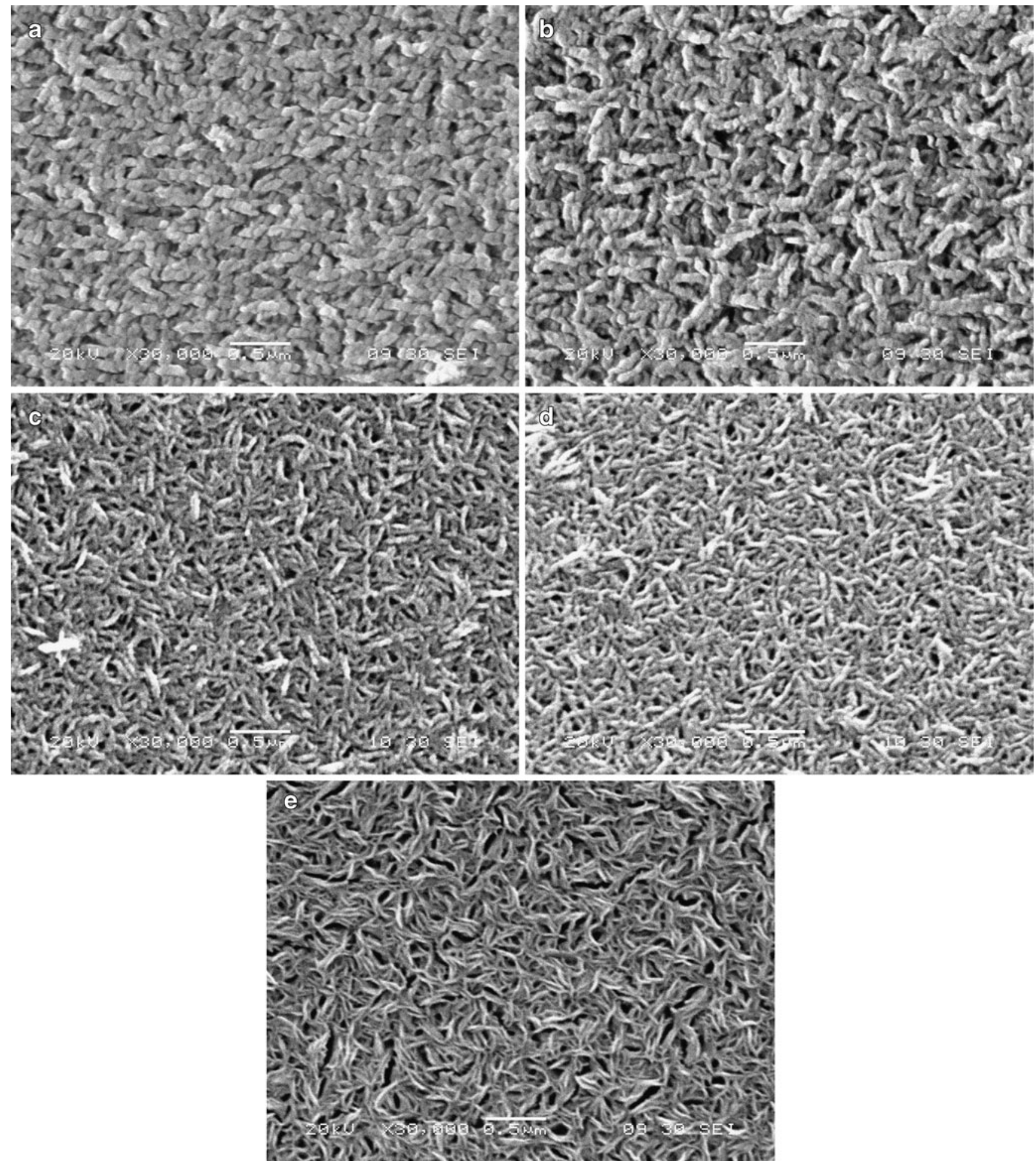

Figure 3. (a)-(e) SEM images of the $\mathrm{CuBiSe}_{2}$ samples.

The electrical properties of the as prepared films such as variation of (i) electrical conductivity with temperature, (ii) activation energy with change of $\mathrm{Cu} / \mathrm{Bi}$ ratio, and (iii) thermoelectric power with temperature were studied. The increase of electrical conductivity with temperature reveals the semiconduct- ing nature of $\mathrm{CuBiSe}_{2}$ films, which may be attributed to the higher amount of copper in a particular compound.

The activation energy goes on decreasing with the increase of copper concentration in $\mathrm{CuBiSe}_{2}$. The decrease in activation energy may be due to increase of conductivity of the samples 
Table 2. Effect of $\mathrm{Cu} / \mathrm{Bi}$ ratios on diameter and length of nanorods.

\begin{tabular}{llccc}
\hline Sample no. & Figure & $\mathrm{Cu} / \mathrm{Bi}$ at $\%$ & Diameter of the rod (nm) & Length of the rod (nm) \\
\hline 1. & $\mathrm{a}$ & 0.13 & 83.33 & 256 \\
2. & $\mathrm{~b}$ & 0.47 & 76.65 & 333 \\
3. & $\mathrm{c}$ & 0.61 & 61.66 & 373 \\
4. & $\mathrm{~d}$ & 0.94 & 48.61 & 385 \\
5. & $\mathrm{e}$ & 1.74 & 41.66 & 439 \\
\hline
\end{tabular}
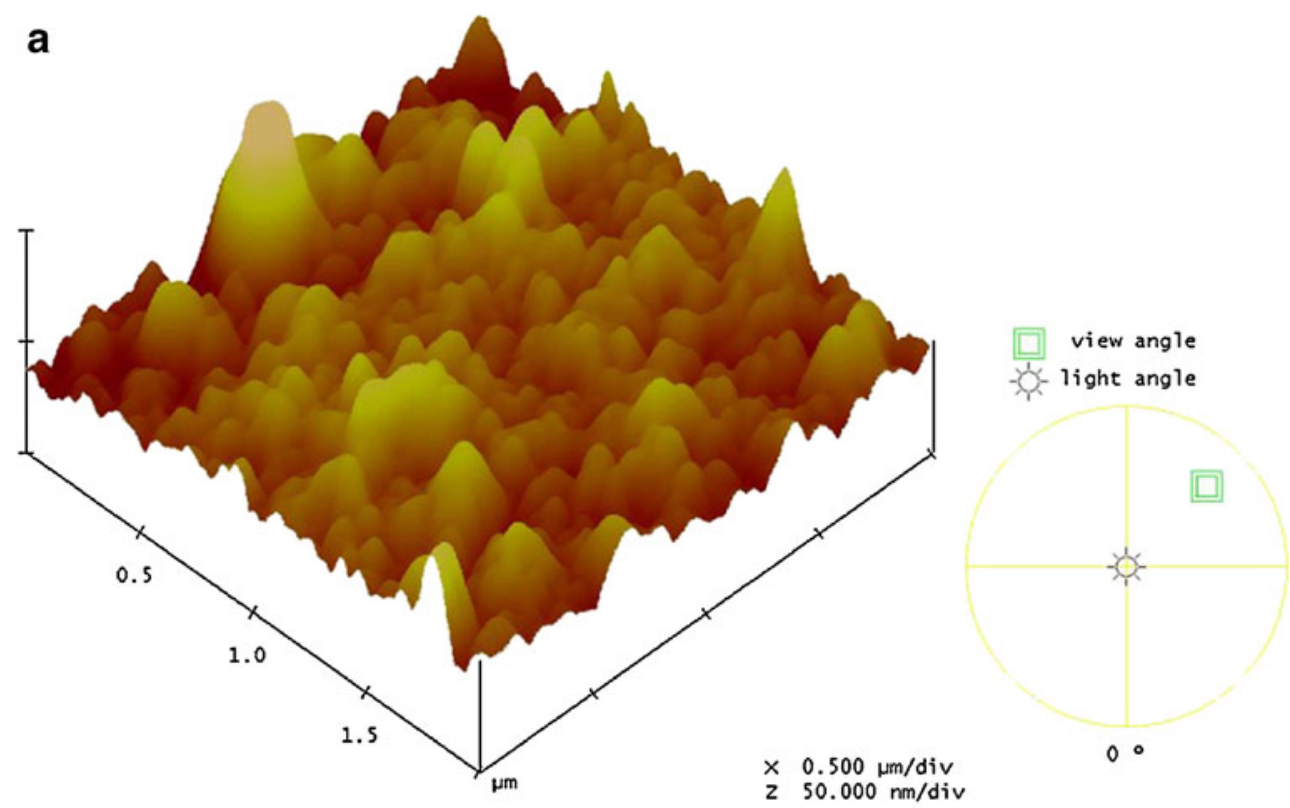

cubisea2.002

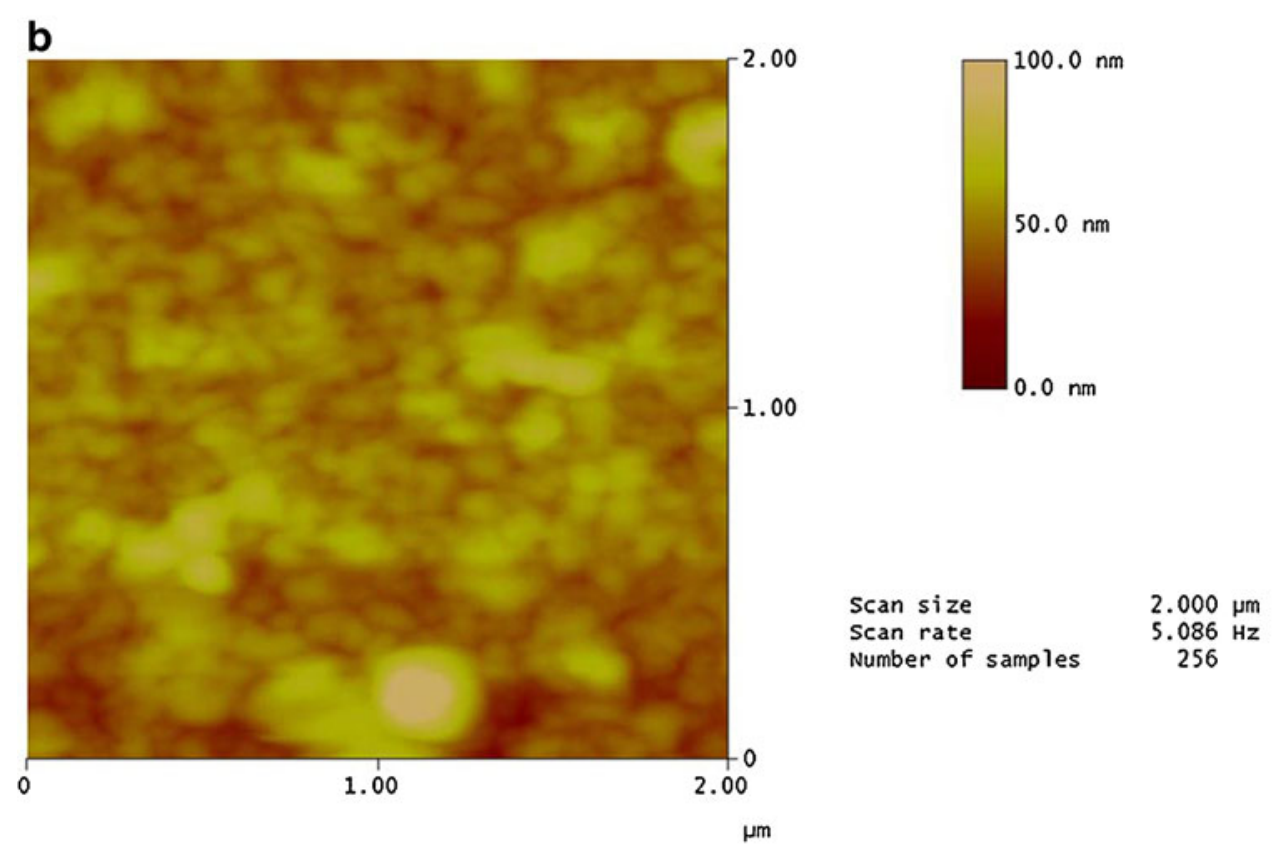

cubisea2.002

Figure 4. AFM pictures of sample 2. 


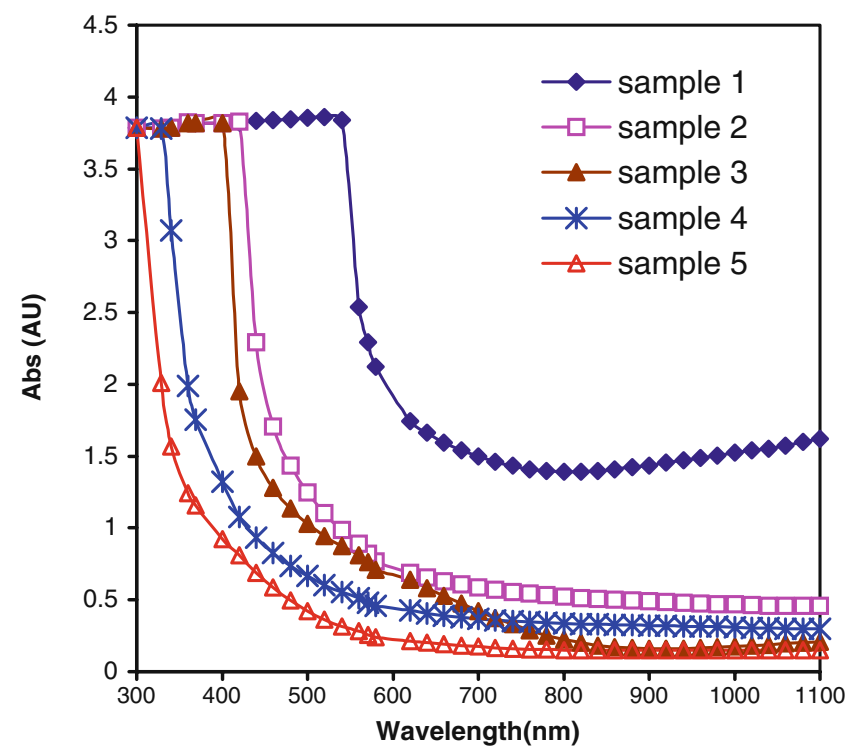

Figure 5. Plot of optical absorbance vs wavelength $\lambda(\mathrm{nm})$.

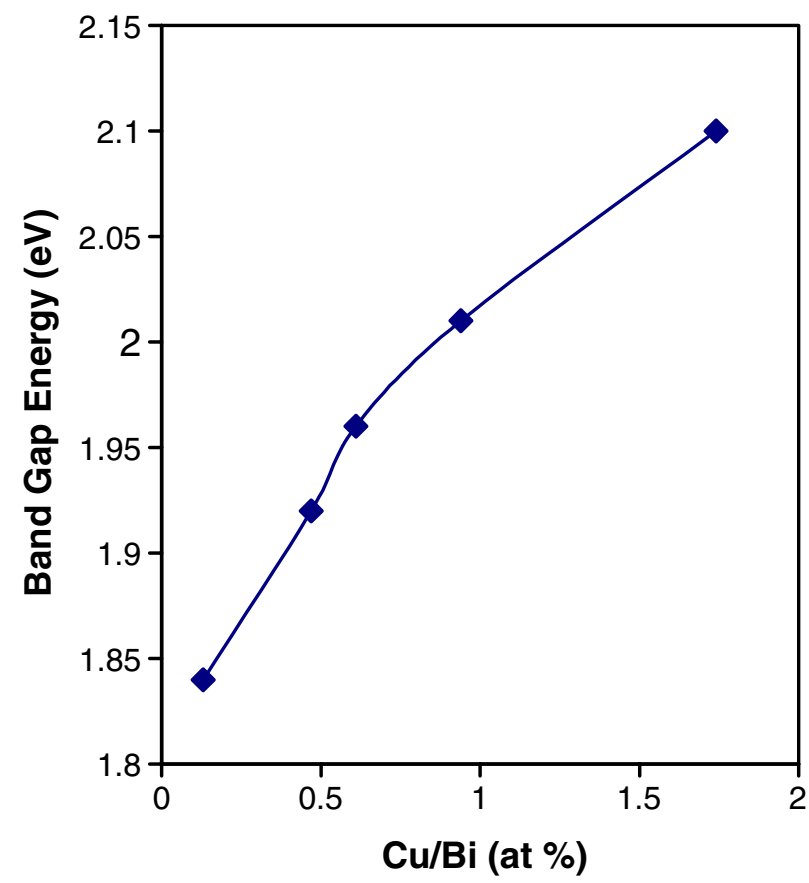

Figure 6. Effect of $\mathrm{Cu} / \mathrm{Bi}$ ratio on bandgap energy.

Table 3. Dependence of bandgap energies on $\mathrm{Cu} / \mathrm{Bi}$.

\begin{tabular}{lccc}
\hline $\begin{array}{l}\text { Sample } \\
\text { no. }\end{array}$ & $\begin{array}{l}\mathrm{Cu} / \mathrm{Bi} \\
(\mathrm{at} \%)\end{array}$ & $\begin{array}{l}\text { Film thickness } \\
(\mathrm{nm})\end{array}$ & $\begin{array}{l}\text { Bandgap energy } \\
(\mathrm{eV})\end{array}$ \\
\hline 1. & $0 \cdot 13$ & 215 & $1 \cdot 84$ \\
2. & 0.47 & 237 & $1 \cdot 92$ \\
3. & 0.61 & 268 & $1 \cdot 96$ \\
4. & 0.94 & 299 & $2 \cdot 01$ \\
5. & 1.74 & 315 & $2 \cdot 10$ \\
\hline
\end{tabular}

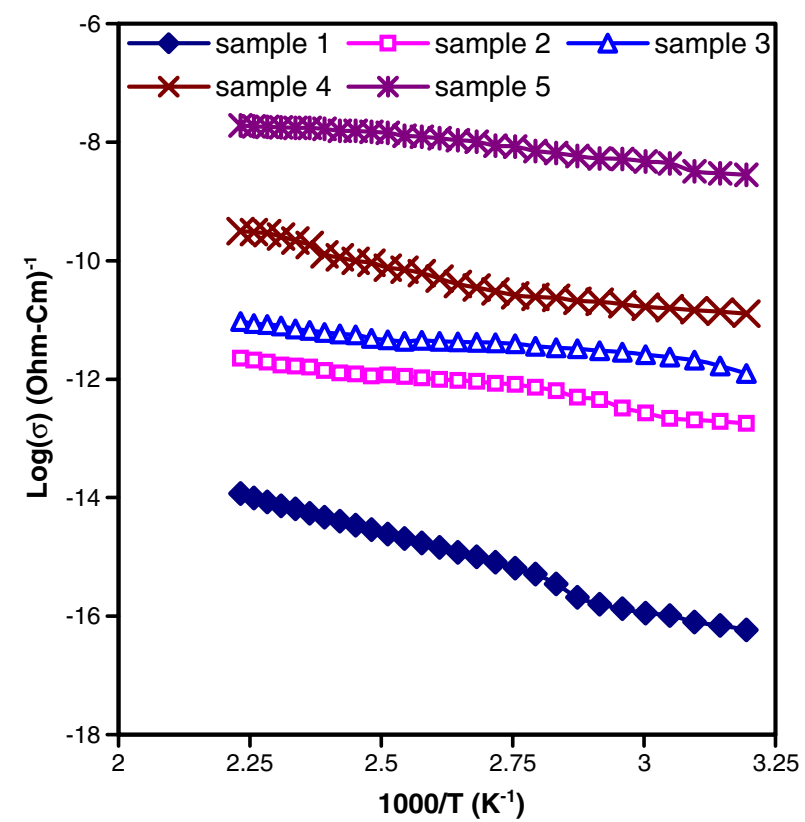

Figure 7. Variation of electrical conductivity with temperature.

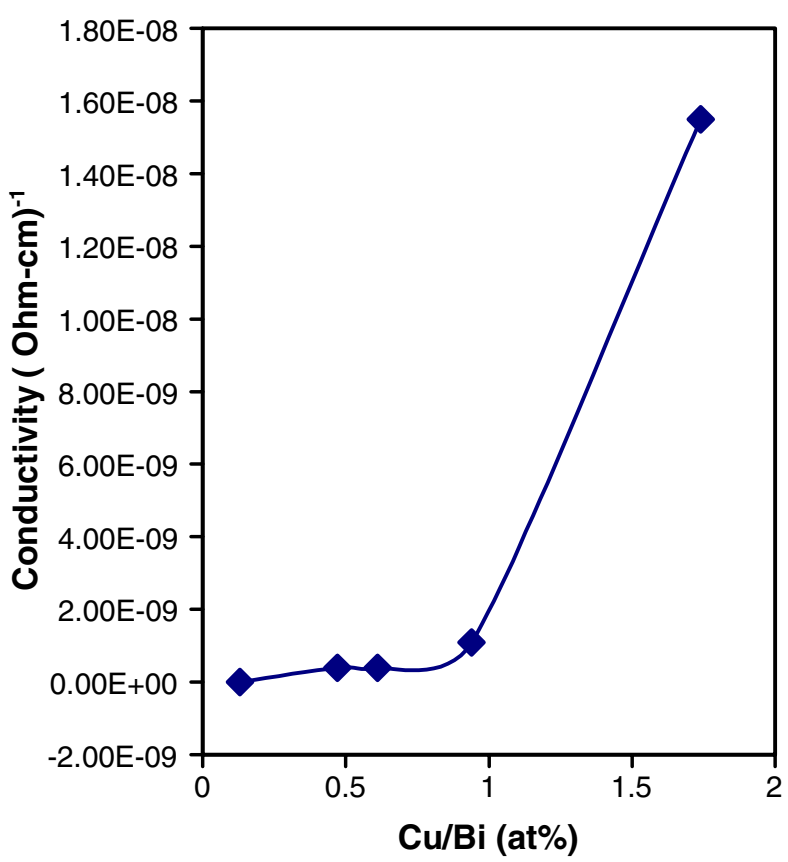

Figure 8. Variation of electrical conductivity with $\mathrm{Cu} / \mathrm{Bi}$ ratio at $448 \mathrm{~K}$.

Table 4. Dependence of conductivity and activation energies on $\mathrm{Cu} / \mathrm{Bi}$.

\begin{tabular}{lrrcc}
\hline $\begin{array}{l}\text { Sample } \\
\text { no. }\end{array}$ & $\begin{array}{l}\mathrm{Cu} / \mathrm{Bi} \\
\text { at } \%\end{array}$ & $\begin{array}{l}\text { Film } \\
\text { thickness } \\
(\mathrm{nm})\end{array}$ & $\begin{array}{l}\text { Conductivity }(\sigma)(\Omega- \\
\mathrm{cm})^{-1}(\text { at } 448 \mathrm{~K})\end{array}$ & $\begin{array}{l}\text { Activation } \\
\text { energy }(\mathrm{eV})\end{array}$ \\
\hline 1. & $0 \cdot 13$ & 215 & $1 \cdot 17 \mathrm{E}-14$ & $0 \cdot 49$ \\
2. & $0 \cdot 47$ & 237 & $4 \cdot 00 \mathrm{E}-10$ & $0 \cdot 28$ \\
3. & $0 \cdot 61$ & 268 & $6 \cdot 10 \mathrm{E}-09$ & $0 \cdot 22$ \\
4. & 0.94 & 299 & $1 \cdot 10 \mathrm{E}-09$ & $0 \cdot 19$ \\
5. & $1 \cdot 74$ & 315 & $1 \cdot 55 \mathrm{E}-08$ & $0 \cdot 17$ \\
\hline
\end{tabular}




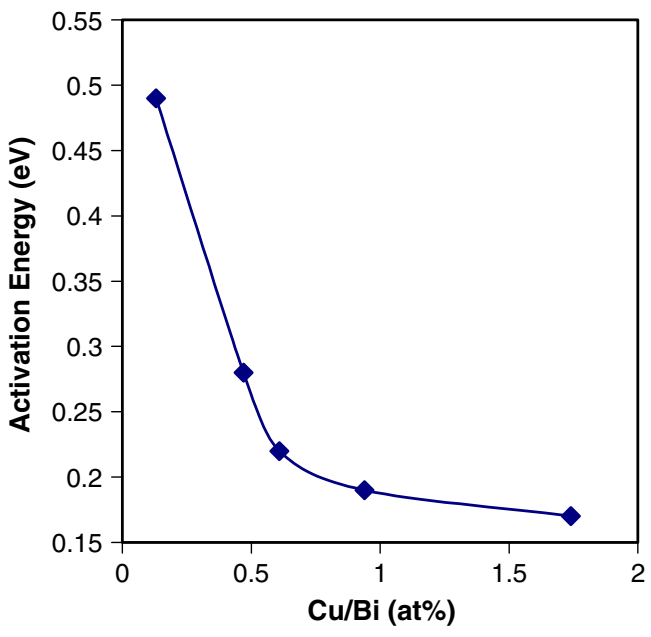

Figure 9. Variation of activation energy with $\mathrm{Cu} / \mathrm{Bi}$ ratio.

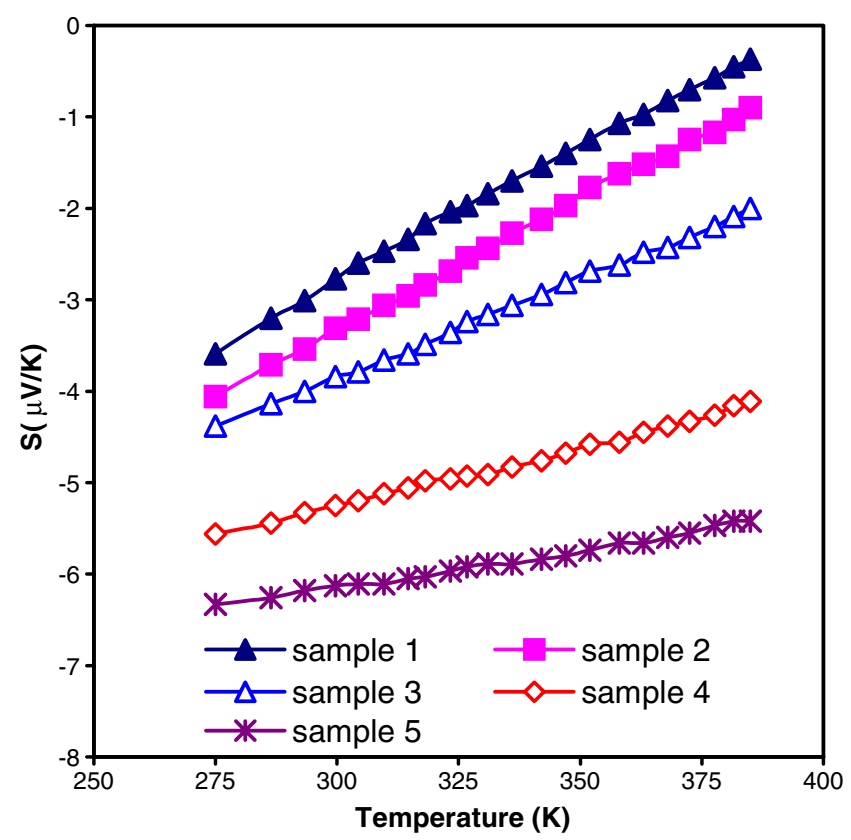

Figure 10. Temperature dependence of thermoelectric power of various $\mathrm{CuBiSe}_{2}$ samples.

Table 5. Dependence of carrier concentration and mobility on $\mathrm{Cu} / \mathrm{Bi}$ ratio.

\begin{tabular}{lcc}
\hline $\begin{array}{l}\mathrm{Cu} / \mathrm{Bi} \\
\text { at } \%\end{array}$ & $\begin{array}{l}\text { Carrier concentration at } \\
300 \mathrm{~K}\left(\mathrm{~cm}^{-3}\right)\end{array}$ & $\begin{array}{l}\text { Mobility }(\mu) \text { at } 300 \mathrm{~K} \\
\left(\mathrm{~cm}^{2} \mathrm{~V}^{-1} \mathrm{~s}^{-1}\right)\end{array}$ \\
\hline $0 \cdot 13$ & $9 \cdot 9 \times 10^{15}$ & $1 \cdot 33 \times 10^{-08}$ \\
$0 \cdot 47$ & $2 \cdot 2 \times 10^{16}$ & $3.08 \times 10^{-09}$ \\
$0 \cdot 61$ & $2 \cdot 7 \times 10^{16}$ & $1 \cdot 64 \times 10^{-10}$ \\
$0 \cdot 94$ & $3.9 \times 10^{16}$ & $2.63 \times 10^{-11}$ \\
$1 \cdot 74$ & $9 \cdot 1 \times 10^{17}$ & $4.07 \times 10^{-12}$ \\
\hline
\end{tabular}

Table 6. Dependence of TEP on $\mathrm{Cu} / \mathrm{Bi}$.

\begin{tabular}{lcc}
\hline Sample no. & $\mathrm{Cu} / \mathrm{Bi}$ at $\%$ & $\mathrm{TEP}(\mathrm{S})(\mu \mathrm{V} / \mathrm{K})($ at $385 \mathrm{~K})$ \\
\hline 1. & 0.13 & -0.37 \\
2. & 0.47 & -0.9 \\
3. & 0.61 & -2 \\
4. & 0.94 & -4.11 \\
5. & 1.74 & -5.42 \\
\hline
\end{tabular}

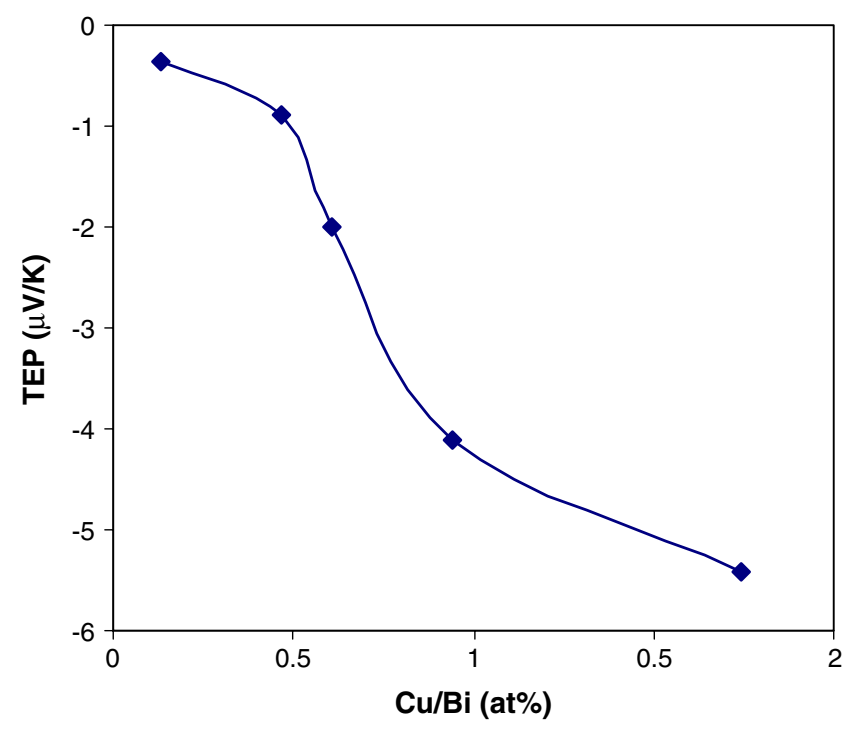

Figure 11. Variation of TEP with $\mathrm{Cu} / \mathrm{Bi}$ ratio at a temperature of $385 \mathrm{~K}$.

with increase of $\mathrm{Cu}$ concentration. It would be easier for electrons to move in the medium having larger conductivity.

\section{Conclusions}

(I) Copper bismuth diselenide films were deposited on to glass substrate by simple chemical bath deposition technique.

(II) The films obtained were uniform and had good adherence to the substrate.

(III) The EDAX of the film indicated that the films were nonstoichiometric.

(IV) AFM observations indicated that the films were relatively smooth.

(V) The values of bandgap energy go on increasing with the increase of $\mathrm{Cu} / \mathrm{Bi}$ ratio.

(VI) The increase in conductivity with the increase in temperature indicated that the films were semiconducting in nature.

(VII) The activation energies were decreasing with the increase of $\mathrm{Cu} / \mathrm{Bi}$ ratio.

(VIII) Negative values of TEP indicated that the films were of $n$ type.

(IX) The value of carrier concentration increases and mobility decreases with the increase of $\mathrm{Cu} / \mathrm{Bi}$ ratio at $300 \mathrm{~K}$. 


\section{Acknowledgements}

The authors are thankful to Head, Department of Physics and Principal, Pratap College, Amalner, for providing laboratory facilities for this work.

The authors are grateful to Dr Ajay Gupta, Centre Director, IUC, Indore, for giving consent for completing part of this work at the consortium. One of the authors (RHB) acknowledges the University Grants Commission, Western Region, Pune, for the award of a teacher fellowship under the 10th plan.

\section{References}

Abdelghany A, Abdelmohsen N, Abou El Ela A H and Abdelwahab D M 1990 Indian. J. Pure \& Appl. Phys. 28329
Abou El-Ela A H and Abdelmohsen N 1982 Appl. Phys. A (Germany) 2939

Chavan S and Sharma R 2005 J. Phys. \& Chem. 661721

Garica V M, Nair P K and Nair M T S 1999 J. Cryst. Growth 203113

Lokhande C D, Ennaoui A, Patil P S, Giersig M, Diesner K, Muller M and Tributsch H 1991 Thin Solid Films 3408

Pawar S H, Pawar A J and Bhosale P N 1986 Bull. Mater. Sci. 8423

Shay J L and Wernick J M 1975 Ternary chalcopyrite semiconductors: Growth, electronic properties, and applications (Oxford and New York: Pergamon Press)

Sonawane P S, Wani P A, Patil L A and Seth T 2004 Mater. Chem. \& Phys. 84221

Sutrave D S, Shahane G S, Dargad J S and Deshmukh L P 1996 Indian J. Pure \& Appl. Phys. 34506

Sutrave D S, Shahane G S, Patil V B and Deshmukh L P 2000 Mater. Chem. \& Phys. $\mathbf{6 5} 298$

Vogel A I 1978 A text book of quantitative inorganic analysis (England: Elbs and Longman) 4 ed., pp. 231, 374, 462 